\title{
Comparison of risk prediction using the CKD-EPI equation and the MDRD Study equation for estimated glomerular filtration rate
}

\author{
Kunihiro Matsushita, MD, PhD, Bakhtawar K. Mahmoodi, MD, PhD, Mark Woodward, PhD, \\ Jonathan R. Emberson, PhD, Tazeen H. Jafar, MD, MPH, Sun Ha Jee, PhD, MHS, Kevan R. \\ Polkinghorne, FRACP, MClinEpi, PhD, Anoop Shankar, MD, MPH, PhD, David H. Smith, \\ RPh, PhD, Marcello Tonelli, MD, SM, David G. Warnock, MD, Chi-Pang Wen, MD, MPH, \\ DrPH, Josef Coresh, MD, PhD, Ron T. Gansevoort, MD, PhD, Brenda R. Hemmelgarn, MD, \\ PhD, Andrew S. Levey, MD, and for the Chronic Kidney Disease Prognosis Consortium \\ Department of Epidemiology, Johns Hopkins Bloomberg School of Public Health, Baltimore, \\ Maryland (Drs. Matsushita, Mahmoodi, Woodward, Coresh); George Institute, University of \\ Sydney, Australia (Dr. Woodward); Clinical Trial Service Unit \& Epidemiological Studies Unit \\ (CTSU), Oxford University, Oxford, United Kingdom (Dr. Emberson); Department of Medicine, \\ Aga Khan University, Karachi, Pakistan (Dr. Jafar); Department of Epidemiology and Health \\ Promotion, Institute for Health Promotion, Graduate School of Public Health, Yonsei University, \\ Seoul, Korea (Dr. Jee); Department of Nephrology, Monash Medical Centre Victoria, Australia \\ and Department of Medicine, Monash University, Victoria, Australia (Dr. Polkinghorne); \\ Department of Community Medicine, West Virginia University School of Medicine, Morgantown, \\ West Virginia (Dr. Shankar); Center for Health Research, Kaiser Permanente Northwest, \\ Portland, Oregon (Dr. Smith); Departments of Medicine, University of Alberta, Edmonton, Alberta, \\ Canada (Dr. Tonelli); Department of Medicine, University Alabama Birmingham, Birmingham, \\ Alabama (Dr. Warnock); China Medical University Hospital, Taichung, Taiwan and Institute of \\ Population Health Science, National Health Research Institutes, Zhunan, Taiwan (Dr. Wen); \\ Department of Nephrology, University Medical Center Groningen, Groningen, the Netherlands \\ (Drs. Mahmoodi, Gansevoort); Departments of Medicine, University of Calgary, Calgary, Alberta, \\ Canada (Dr. Hemmelgarn); Division of Nephrology, Tufts Medical Center, Boston, \\ Massachusetts, USA (Dr. Levey).
}

\section{Abstract}

Context-The CKD-EPI equation more accurately estimates glomerular filtration rate (eGFR) than the MDRD Study equation using the same variables, especially at higher GFR, but definitive evidence of its risk implications in diverse settings is lacking.

Objective-To evaluate risk implications of eGFR $\mathrm{CKD}_{\text {-EPI }}$ compared to $\mathrm{eGFR}_{\mathrm{MDRD}}$ in populations with a broad range of demographic and clinical characteristics.

Design, Setting, and Participants-Meta-analyses based on data from 1,130,472 adults (aged 18 years or older) from 25 general population, 7 high-risk (of vascular disease), and 13 chronic kidney disease (CKD) cohorts. Data transfer and analyses were conducted between March 2011 and March 2012.

Main Outcome Measures-All-cause mortality (84,482 deaths from 40 cohorts), cardiovascular mortality (22,176 events from 28 cohorts), and end-stage renal disease (ESRD) (7,644 events from 21 cohorts) during 9.4 million person-years of follow-up (median of mean follow-up time across cohorts was 7.4 years).

Correspondence: Chronic Kidney Disease Prognosis Consortium Data Coordinating Center (Principal Investigator, Josef Coresh, MD, PhD), 615 N. Wolfe Street, Baltimore, MD 21205 Tel: 410-955-9917, Fax: 410-955-8086, ckdpc@jhmi.edu. 
Results-eGFR was classified into six categories ( $\geq 90,60-89,45-59,30-44,15-29$, and $<15 \mathrm{ml} /$ $\min / 1.73 \mathrm{~m}^{2}$ ) by both equations. Compared to eGFR $\mathrm{MDRD}, 24.4 \%$ and $0.6 \%$ of participants from general population cohorts were reclassified to a higher and lower eGFR category by the CKDEPI equation, respectively, and the prevalence of CKD stage 3-5 (eGFR $<60 \mathrm{ml} / \mathrm{min} / 1.73 \mathrm{~m}^{2}$ ) was reduced from $8.7 \%$ to $6.3 \% .34 .7 \%$ of participants with eGFR ${ }_{M D R D} 45-59$ were reclassified to eGFR $_{\text {CKD-EPI }}$ 60-89 and had lower incidence rates (per 1,000 person-years) of outcomes compared to those not reclassified ( 9.9 vs. 34.5 for all-cause mortality, 2.7 vs. 13.0 for cardiovascular mortality, and 0.5 vs. 0.8 for ESRD). The corresponding adjusted hazard ratios were 0.80 (95\% confidence interval, 0.74 to 0.86 ) for all-cause mortality, 0.73 ( 0.65 to 0.82 ) for cardiovascular mortality, and 0.49 (0.27 to 0.88) for ESRD. Similar findings were observed in

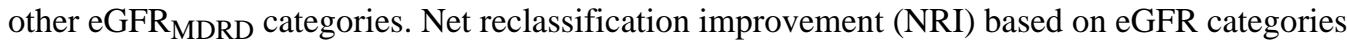
was significantly positive for all outcomes (range from 0.06 to 0.13 , all $P<0.001$ ). NRI was similarly positive in most subgroups defined by age ( $<$ and $ð 65$ years), sex, race/ethnicity (white, Asian, and black), and presence or absence of diabetes and hypertension. The results in high-risk and CKD cohorts were largely consistent with the general population cohorts.

Conclusions-The CKD-EPI equation classified fewer individuals as CKD and more accurately categorized the risk for mortality and ESRD than did the MDRD Study equation across a broad range of populations.

Glomerular filtration rate (GFR) is used in the diagnosis of chronic kidney disease (CKD) ${ }^{1,2}$ and is an independent predictor of all-cause and cardiovascular mortality and kidney failure in a wide range of populations. ${ }^{3-6}$ Clinical guidelines recommend reporting estimated GFR (eGFR) when serum creatinine is measured, ${ }^{1,2}$ and, currently, $84 \%$ of US laboratories report eGFR. ${ }^{7}$ Although the Modification of Diet in Renal Disease (MDRD) Study equation is recommended for estimating GFR, ${ }^{1,2,8,9}$ the Chronic Kidney Disease Epidemiology Collaboration (CKD-EPI) has recently proposed an alternative equation, which applies different coefficients to the same four variables used in the MDRD Study equation (age, sex, race, and serum creatinine). ${ }^{10}$ The new CKD-EPI equation estimates measured GFR more accurately than the MDRD Study equation in most, ${ }^{10-18}$ but not all, ${ }^{19,20}$ studies. However; only $4 \%$ of US laboratories reporting eGFR used the CKD-EPI equation in June 2011; $92 \%$ of laboratories still used the MDRD Study equation and 4\% used other equations. ${ }^{7}$

A few studies suggest that the better estimation of GFR by the CKD-EPI equation is reflected in better clinical risk prediction than the MDRD Study equation. ${ }^{21-24}$ However, these studies include predominantly white people with higher levels of kidney function. Also, implications of the CKD-EPI equation in the elderly have yet to be elucidated. ${ }^{25,26}$ The objective of this collaborative study was to comprehensively evaluate whether eGFR computed by the CKD-EPI equation predicts risk for adverse outcomes more accurately than the MDRD Study equation in a broad range of populations. Such information will help clinicians, laboratories and policy makers decide whether eGFR reporting should be based on the MDRD Study or the CKD-EPI equation.

\section{METHODS}

\section{Study Design}

Details of the Chronic Kidney Disease Prognosis Consortium (CKD-PC) were described previously. ${ }^{3-6}$ To be included in the consortium, a study had to have at least 1,000 participants (not applied to studies only enrolling CKD patients [CKD cohorts] ${ }^{6}$ ), information at baseline on eGFR and urine albumin levels, and a minimum of 50 events for any of the outcomes of interest. As recommended, ${ }^{1,2}$ we preferentially selected urine albumin-to-creatinine ratio (ACR) as the measure of albuminuria. However, we also 
accepted urine albumin excretion and urine protein-to-creatinine ratio (PCR) as well as a qualitative measurement using dipstick. ${ }^{1}$ This analysis consists of data from 45 cohorts $(25$ general population cohorts, seven high-risk cohorts with participants selected for cardiovascular or kidney disease risk factors, and 13 CKD cohorts). Data transfer (from collaborating cohorts to the CKD-PC Data Coordinating Center) and analyses for the present study were conducted between March 2011 and March 2012. This study is based on secondary data analysis of pre-existing, de-identified/de-linked dataset, and was approved by the Institutional Review Board at the Johns Hopkins Bloomberg School of Public Health. Information about ethical review of individual studies is available in the publications of the constituent cohorts. ${ }^{21,24,27-69}$

\section{Estimation of GFR}

We calculated eGFR from serum creatinine standardized to isotope dilution mass spectrometry (IDMS) using the MDRD Study equation ${ }^{9}$ and the CKD-EPI equation. ${ }^{10}$ For studies in which creatinine measurement was not standardized to IDMS, we reduced the creatinine levels by $5 \%$, the calibration factor used to adjust non-standardized MDRD Study samples to IDMS. ${ }^{70}$

\section{Covariates}

Diabetes mellitus was defined as fasting glucose $\geq 7.0 \mathrm{mmol} / \mathrm{L}$, non-fasting glucose $\geq 11.1$ $\mathrm{mmol} / \mathrm{L}$, hemoglobin A1c $26.5 \%$, use of glucose lowering drugs, or self-reported diabetes. Hypertension was defined as systolic blood pressure $\geq 140 \mathrm{mmHg}$ or diastolic blood pressure $\geq 90 \mathrm{mmHg}$ or use of antihypertensive medication. Hypercholesterolemia was defined as total cholesterol $\geq 5.0 \mathrm{mmol} / \mathrm{L}$ in people with prior cardiovascular disease (CVD) and as $\Varangle 6.0$ $\mathrm{mmol} / \mathrm{L}$ otherwise or use of lipid lowering drugs. CVD history was defined as a history of myocardial infarction, coronary revascularization, heart failure or stroke. Smoking was dichotomized as current versus former/non-smokers. Race/ethnicity was categorized as white, Asian, black, Hispanic, and others.

\section{Outcomes}

The outcomes of interest were all-cause mortality, cardiovascular mortality, and end-stage renal disease (ESRD). Cardiovascular mortality was defined as death due to myocardial infarction, heart failure, sudden cardiac death, or stroke. ESRD was defined as start of renal replacement therapy or death due to kidney disease other than acute kidney injury.

\section{Statistical Analyses}

Statistics were first obtained within each study and then were meta-analyzed across studies by a random-effects model. Analyses were restricted to subjects aged 18 years or older. Any subject with missing values for eGFR or albuminuria at baseline was excluded. Missing values for all other covariates were estimated by mean imputation. The analysis overview and analytic notes for individual studies are described in eAppendix 2. Heterogeneity was quantified using the $\mathrm{X}^{2}$ test for heterogeneity and the $\vec{I}^{2}$ statistic. We conducted metaregression analysis with a random-effects model to explore sources of heterogeneity. General population, high-risk and CKD cohorts were meta-analyzed separately.

We evaluated the eGFR distribution and eGFR-risk relationship for the two equations separately. Cox proportional hazards models were fitted with eGFR linear splines (knots at $30,45,60,75,90$, and 105 [this knot was not applied to CKD cohorts] $\mathrm{ml} / \mathrm{min} / 1.73 \mathrm{~m}^{2}$ ). All Cox models adjusted for age, sex, race/ethnicity (blacks vs. non-blacks), smoking, history of CVD, systolic blood pressure (continuous), diabetes, serum total cholesterol concentration (continuous), body mass index (continuous), and albuminuria (log-transformed ACR and 
PCR as continuous variables or dipstick as a categorical variable [negative, trace, $1+, 2+$, and $33+]$ ). From these models, hazard ratio was computed for each $1 \mathrm{ml} / \mathrm{min} / 1.73 \mathrm{~m}^{2}$ of eGFR from 15 to 120 with a reference point at $95 \mathrm{ml} / \mathrm{min} / 1.73 \mathrm{~m}^{2}\left(50 \mathrm{ml} / \mathrm{min} / 1.73 \mathrm{~m}^{2}\right.$ for CKD cohorts). Model discrimination was assessed using a c-statistic which allows for censoring. 71

We cross-tabulated eGFR using clinically relevant categories ( $\geq 90,60-89,45-59,30-44$, $\left.15-29,<15 \mathrm{ml} / \mathrm{min} / 1.73 \mathrm{~m}^{2}\right)^{1,2}$ and evaluated the proportion of participants in each category

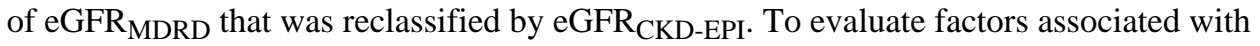
reclassification, baseline characteristics of participants in each study were compared according to the reclassification status by the CKD-EPI equation (reclassified upward to a higher eGFR category, not reclassified, or reclassified downward to a lower eGFR category). Since there were few participants with eGFR $<15 \mathrm{ml} / \mathrm{min} / 1.73 \mathrm{~m}^{2}$ in the general population $(<0.1 \%)$ and high-risk $(0.2 \%)$ cohorts, we only reported results for this eGFR category in the CKD cohorts.

Given that GFR category is a central measure for defining, staging and managing CKD (including indications for referral), ${ }^{1,2}$ we a priori designated the impact of reclassification in clinical eGFR categories as the primary analysis. ${ }^{21-23}$ We assessed risk of clinical outcomes among participants who were reclassified for eGFR categories compared with those who were not reclassified. Overall improvement in reclassification based on clinical eGFR categories was assessed applying net reclassification improvement (NRI). ${ }^{21,72}$ To assess generalizability, we calculated NRI in subgroups according to age ( $<65$ and 265 years old), sex, race/ethnicity (white, Asian, and black), and presence or absence of diabetes and hypertension. Due to sparse data, we could not reliably investigate Hispanics and other racial/ethnic groups. NRI was also estimated in subgroups according to albuminuria levels. All analyses were conducted using Stata/MP 11.2 software (www.stata.com) and a $P$-value of less than 0.05 was considered statistically significant.

\section{RESULTS}

\section{Study Characteristics}

Participants from 45 cohorts were from 40 countries/regions of Asia, Europe, North and South America, Middle East and Oceania. Baseline characteristics of each cohort are shown in eTable 1. Overall, 1,130,472 adults (940,366 from general population, 151,494 from highrisk, and 38,612 from CKD cohorts) were followed for 9,415,863 person-years (the median of mean follow-up time across collaborating cohorts was 7.4 years [interquartile range, 4.2 to 10.5 years]). Forty cohorts reported on 84,482 deaths $(61,770$ from general population, 13,693 from high-risk, and 9,019 from CKD cohorts); 28 cohorts reported on 22,176 CVD deaths (17,009 from general population, 4,271 from high-risk, and 896 from CKD cohorts); and 21 cohorts reported on 7,644 ESRD events (730 from general population, 954 from high-risk, and 5,960 from CKD cohorts).

\section{Distribution and Relative Risk according to eGFR by each Equation}

Mean eGFR was higher computed by the CKD-EPI equation than the MDRD Study equation in the general population ( $88.9 \mathrm{vs} .81 .5 \mathrm{ml} / \mathrm{min} / 1.73 \mathrm{~m}^{2}$, FIGURE 1A) and the high-risk ( 84.6 vs. $80.6 \mathrm{ml} / \mathrm{min} / 1.73 \mathrm{~m}^{2}$, eFigure $1 \mathrm{~A}$ ) cohorts but was comparable in the CKD cohorts ( 41.4 vs. $40.6 \mathrm{ml} / \mathrm{min} / 1.73 \mathrm{~m}^{2}$ ) (eFigure $2 \mathrm{~A}$ ). The shift of distribution toward higher eGFR by the CKD-EPI equation was more evident in younger people ( $<65$ years), female, and non-blacks (eFigures 3-5). Accordingly, the prevalence of CKD stages 3 to 5 $\left(<60 \mathrm{ml} / \mathrm{min} / 1.73 \mathrm{~m}^{2}\right)$ was lower by the CKD-EPI equation than the MDRD Study equation in the general population $(6.3 \%$ vs. $8.7 \%)$ and high-risk (14.6\% vs. $17.7 \%)$ cohorts. The 
lower prevalence of CKD stages 3 to 5 by the CKD-EPI equation was observed in most of the individual cohorts with a small increase in only two cohorts of elderly subjects $^{30,39}$ (eFigure 6).

The pattern of the eGFR-risk relationship was similar for both equations in the general population cohorts after adjusting for potential confounders (Figure 1B-D). However, the adjusted hazard ratio of lower eGFR compared with eGFR of $95 \mathrm{ml} / \mathrm{min} / 1.73 \mathrm{~m}^{2}$ became significant at a higher level for eGFR CKD-EPI $_{\text {than for eGFR }}$ MDRD, particularly for cardiovascular mortality ( $\left.77 \mathrm{vs.} 68 \mathrm{ml} / \mathrm{min} / 1.73 \mathrm{~m}^{2}\right)$ and ESRD ( $82 \mathrm{vs} .70 \mathrm{ml} / \mathrm{min} / 1.73 \mathrm{~m}^{2}$ ). Within the range of eGFR $<45 \mathrm{ml} / \mathrm{min} / 1.73 \mathrm{~m}^{2}$, the hazard ratios were largely comparable between both equations for the mortality outcomes. The steeper risk gradient along with low eGFR was more evident in unadjusted analysis for mortality (eFigure 7). The higher risk of all-cause and cardiovascular mortality in the higher eGFR range $\left(105-120 \mathrm{ml} / \mathrm{min} / 1.73 \mathrm{~m}^{2}\right)$ was more pronounced for the CKD-EPI equation than the MDRD Study equation. This effect was not observed in unadjusted analysis. Similar eGFR-risk relationships were observed in the high-risk and CKD cohorts (eFigures 1B-D and 2B-D), but the higher risk at higher levels of eGFR was not evident. Using these models with eGFR splines, traditional risk factors, and albuminuria, c-statistics, which focus on ranking alone and ignore absolute levels and categories, ${ }^{73}$ were almost identical for the CKD-EPI and MDRD Study equations in all three types of cohort $(0.783$ [0.758 to 0.807 ] vs. 0.783 [0.759 to 0.808$]$ for all-cause mortality, 0.835 [0.800 to 0.869$]$ vs. 0.835 [0.801 to 0.869 ] for cardiovascular mortality and 0.920 [0.888 to 0.953 ] vs. 0.919 [0.885 to 0.952] for ESRD in the general population cohorts, respectively) (eTable 2).

\section{eGFR Category Reclassification and its Risk Implications}

In the general population cohorts, $25.0 \%$ of participants were reclassified by the CKD-EPI equation ( $24.4 \%$ to a higher eGFR category and $0.6 \%$ to a lower eGFR category) (FIGURE 2). Most reclassification occurred among participants with eGFR ${ }_{M D R D}$ between $45-89 \mathrm{ml} /$ $\min / 1.73 \mathrm{~m}^{2}$. A similar reclassification pattern was observed in the high-risk cohorts, although there was less reclassification (15.4\% upward and $1.2 \%$ downward, eFigure 8 ). In the CKD cohorts, we observed much less upward reclassification (6.6\%) but slightly more downward reclassification (3.2\%) by the CKD-EPI equation (eFigure 9).

Participants who were reclassified upward to a higher eGFR category by the CKD-EPI equation were more likely to be younger, female, and non-black, and, thus, to have fewer comorbid conditions such as hypertension, diabetes, and clinically significant albuminuria as compared to individuals who remained in the same eGFR category (Table 1 and eTable 3 ). In contrast, the participants reclassified downward to a lower eGFR category by the CKDEPI equation were much older than those who were not reclassified in most studies (mean age in general population cohorts, 77 years vs. 49 years). Blacks tended to be reclassified less frequently (in either direction) in the general population cohorts but, at lower GFR range (CKD cohorts), were reclassified downward more frequently as compared to nonblacks.

Participants in general population cohorts who were reclassified upward and downward by the CKD-EPI equation had consistently lower and higher incidence rates for all outcomes, respectively, than those who remained in the same eGFR category (Table 2). This association remained the same even after adjustment for potential confounders, with only a few exceptions (none of which were significant). When we focused on clinically important upward reclassification from CKD stage $3 \mathrm{a}\left(\mathrm{eGFR} 45-59 \mathrm{ml} / \mathrm{min} / 1.73 \mathrm{~m}^{2}\right.$ ) to mildly reduced eGFR $\left(60-89 \mathrm{ml} / \mathrm{min} / 1.73 \mathrm{~m}^{2}\right)$, this reclassification was associated with lower incidence rates compared to no reclassification (incidence rate per 1,000 person-years, 9.9 vs. 34.5 [difference, -24.6] for all-cause mortality, 2.7 vs. 13.0 [-10.3] for cardiovascular mortality, 
and 0.5 vs. 0.8 [ -0.3 ] for ESRD). Of note, this reclassification was associated with $20-51 \%$ lower risk of these outcomes even after the adjustment for traditional risk factors and albuminuria. We obtained similar results for the groups below and above age 65 years (eTables 4 and 5). Among the statistically significant reclassifications in Table 2, heterogeneity across studies was minimal to moderate $\left(I^{2}=0.0-52.5 \%, P\right.$-values range from 0.82 to 0.006 ). Similar findings were observed in the high-risk (eTable 6 ) and CKD cohorts (eTable 7). For ESRD, analysis with mortality as a competing risk provided similar findings (eTable 8).

In the general population cohorts, NRI was significantly positive (favoring the CKD-EPI equation) for all outcomes ( 0.11 [95\% CI, 0.09-0.13] for all-cause mortality, 0.13 [0.09-0.16] for cardiovascular mortality, and 0.06 [0.02-0.10] for ESRD) (FIGURE 3). There was high heterogeneity between individual cohorts for overall NRI ( $P^{2}=71 \%$ to $97 \%$, all $P<0.01)$. However, this heterogeneity reflected quantitative rather than qualitative differences, since the CKD-EPI equation was favored in almost all general population studies (eFigures 10-12). We conducted meta-regression analysis with covariates (eTable 9). Studies with higher mean age and prevalence of diabetes tended to have lower NRI for cardiovascular mortality (eFigures 13 and 14). NRI for other associations did not vary significantly across studies.

NRI was positive in most of the subgroups according to age, sex, race/ethnicity and presence or absence of diabetes and hypertension (FIGURE 3). NRI was comparable between females and males and between ages $<65$ years and $\succ 65$ years except for a lower NRI in age $\succ 65$ years for ESRD. NRI was positive even in the age category of $\geq 75$ years for all-cause mortality $(0.03$ [ $95 \% \mathrm{CI}, 0.02$ to 0.05$])$ and cardiovascular mortality (0.02 [0.01 to 0.03$])$. NRI was negative but not significant for ESRD ( -0.04 [ -0.10 to 0.02 ], $P=0.149)$. NRI for mortality outcomes was lower in blacks as compared to whites and Asians but still significantly favored the CKD-EPI equation. With further stratification by the combination of these demographic variables, NRI was positive (favoring the CKD-EPI equation) in 33 out of 36 comparisons and was statistically significant in 17 comparisons (eTable 10). None of three negative NRIs (favoring the MDRD Study equation) were significant. Similarly, NRI was positive in most subgroups in the high-risk and CKD cohorts (eFigures 15 and 16 and eTables 11 and 12). NRI was also positive in most subgroups defined according to albuminuria level (eTable 13).

\section{COMMENT}

In our data from more than 1 million participants residing in 40 countries/regions, approximately one quarter of participants were reclassified to a higher eGFR category by the CKD-EPI equation compared to the MDRD Study equation (24.4\% in the general population, $15.4 \%$ in high-risk, and $6.6 \%$ in CKD cohorts), lowering the prevalence of CKD in all cohorts except for the elderly. Participants who were reclassified upward had lower risks of mortality and ESRD as compared to those not reclassified even after adjusting for age, sex, race/ethnicity and other potential confounders. Individuals who were reclassified downward $(0.7 \%)$ had higher risk than those who were not reclassified. Positive NRIs also support better overall reclassification by the CKD-EPI equation. Although we observed quantitative heterogeneity in some analyses, most of the studies were in agreement with the pooled results (eFigures 10-12). Importantly, a better risk categorization by the CKD-EPI equation as compared to the MDRD Study equation was consistent in almost all subgroups defined by age, sex, race/ethnicity, and clinical characteristics.

Our results confirm and extend results from previous literature. ${ }^{21-24}$ First, we observed that the CKD-EPI equation is a better predictor of risk than the MDRD Study equation in CKD 
cohorts as well as in cohorts with higher eGFR. Improved or similar performance across the range of eGFR is important for clinical implementation. Second, although the elderly were less often reclassified by the CKD-EPI equation as compared to younger people, their future risk was also more correctly classified. Third, we found that the CKD-EPI equation predicts clinical risk more accurately than the MDRD Study equation in Asians. Although there is debate about which eGFR equation to use in Asia, ${ }^{74,75}$ our results suggest that the CKD-EPI equation would be a better option for risk prediction than the MDRD Study equation.

Fourth, we showed that the CKD-EPI equation categorizes risk slightly more accurately than or at least as well as the MDRD Study equation in blacks, even though reclassification is less common in blacks than in whites and Asians. Fifth, we showed that the CKD-EPI equation provides more accurate risk categorization than the MDRD Study even after considering albuminuria, a measure of kidney damage. Recent reports suggest using albuminuria in addition to GFR for CKD staging and risk classification. ${ }^{76,77}$ Our findings suggest the CKD-EPI equation will be more useful than the MDRD Study equation for this application. Finally, we showed improved risk prediction for ESRD, in addition to mortality and cardiovascular disease shown in most of the previous studies. ${ }^{21-24}$

The CKD-EPI and MDRD Study equations estimate the same physiologic function (GFR) using identical variables, thus the comparison of outcome prediction by two equations differs from the more common comparison of two models with and without a new biomarker. Since the same variables appear in both equations here, the difference in predicted risk between the two equations should not be expected to be as large as would be sought when adding a new biomarker. Consequently, we did not anticipate improvements in less sensitive statistics such as the c-statistic, which ignore absolute levels and categories and focus on ranking alone. ${ }^{73}$ This is particularly the case when age, sex, and race/ethnicity are included in the prediction model, since coefficients for these variables can compensate for worse prediction by eGFR $\mathrm{MDRD}_{\text {compared with eGFR }}{\mathrm{CKD}-\mathrm{EPI}^{21}}^{21}$.

From another perspective, the use of the identical variables in the CKD-EPI requires no additional laboratory costs and enables relatively easy implementation with computerized algorithms. Therefore, a significant overall improvement in risk categorization by the CKDEPI equation, even if small, would support its clinical use in place of the MDRD Study equation. At this time, only a small proportion of clinical laboratories in the US have switched to the CKD-EPI equation for eGFR reporting. ${ }^{7}$ In this context, clinically important reclassification crossing the threshold for CKD definition from CKD stage 3a to mildly reduced eGFR $\left(60-89 \mathrm{ml} / \mathrm{min} / 1.73 \mathrm{~m}^{2}\right)$ was observed in one third of individuals with $\mathrm{eGFR}_{\mathrm{MDRD}} 45-59 \mathrm{ml} / \mathrm{min} / 1.73 \mathrm{~m}^{2}$ in our study. In the general population cohorts, these individuals had lower risk of mortality and ESRD as compared to those who were not reclassified (crude incidence rate difference -24.6 to -0.3 per 1,000 person-years and 20-51\% lower adjusted hazard ratio). Given both lower CKD prevalence estimates and better risk categorization, the use of the CKD-EPI equation would contribute to a more efficient allocation of healthcare resources and more targeted prevention and management of CKD complications.

The paradoxically increased mortality risk at higher eGFR is noted in several studies and may be due to confounding by muscle wasting secondary to ill health. ${ }^{21}$ With the CKD-EPI equation, this risk was not evident in unadjusted analysis but was clearly evident after age adjustment suggesting the CKD-EPI equation does not fully overcome this limitation inherent to creatinine-based eGFR equations. Other filtration markers not related to muscle mass such as serum cystatin $\mathrm{C}^{78,79}$ might help to resolve this issue.

Some limitations of the present study should be mentioned. Measurements of creatinine were not standardized in all studies; however, we observed similar results when we limited 
our analysis to studies with serum creatinine measurements standardized to IDMS (data not shown). Most of the participants recorded as blacks were from studies in the US. Although there are various ethnic groups within Asia, e.g., South Asian and Eastern Asian, we analyzed them together. Further analyses will be required for racial/ethnic groups not tested in this study.

Overall, the CKD-EPI creatinine-based equation more accurately classified individuals with respect to risk of mortality and ESRD as compared to the MDRD Study equation. Given more accurate GFR estimation, ${ }^{10}$ lower CKD prevalence estimates, and better risk categorization by the CKD-EPI equation without additional laboratory costs, its implementation for eGFR reporting could contribute to more efficient and targeted prevention and management of CKD-related outcomes.

\section{Supplementary Material}

Refer to Web version on PubMed Central for supplementary material.

\section{Acknowledgments}

Funding/Support: The CKD-PC Data Coordinating Center is underpinned by a program grant from the US National Kidney Foundation (NKF funding sources include Abbott and Amgen). A variety of sources have supported enrollment and data collection including laboratory measurements, and follow-up in the collaborating cohorts of the CKD-PC. These funding sources of the collaborating cohorts are listed in eAppendix 3.

\section{Appendix}

\section{Author Contributions}

Dr. Coresh had full access to all of the data in the study and takes responsibility for the integrity of the data and the accuracy of the data analysis.

Study concept and design: Matsushita, Coresh, Levey.

Acquisition of data: Matsushita, Coresh for CKD-PC with CKD-PC investigators/ collaborators listed below.

Analysis and interpretation of data: Matsushita, Mahmoodi, Woodward, Emberson, Jafar, Jee, Polkinghorne, Shankar, Smith, Tonelli, Warnock, Wen, Coresh, Gansevoort, Hemmelgarn, Levey.

Drafting of the manuscript: Matsushita, Coresh, Levey.

Critical revision of the manuscript for important intellectual content: Matsushita, Mahmoodi, Woodward, Emberson, Jafar, Jee, Polkinghorne, Shankar, Smith, Tonelli, Warnock, Wen, Coresh, Gansevoort, Hemmelgarn, Levey.

Statistical analysis: Matsushita, Woodward, Coresh with the Data Coordinating Center members listed below.

Obtained funding: Matsushita, Coresh for CKD-PC with cohort and collaborator support listed in eAppendix 3.

Administrative, technical, or material support: Matsushita, Mahmoodi, Coresh.

Study supervision: Matsushita, Coresh, Levey. 


\section{Conflict of Interest Disclosures}

All authors have completed and submitted the ICMJE Form for Disclosure of Potential Conflicts of Interest. None of the authors reported conflicts.

\section{CKD-PC investigators/collaborators (eAppendix 1 lists the study acronyms)}

AASK: Jackson Wright, MD, PhD, Case Western Reserve University, United States; Lawrence J. Appel, MD, MPH, Johns Hopkins University, United States; Tom Greene, PhD, University of Utah, United States; Brad C. Astor, PhD, MPH, University of Wisconsin, United States; ADVANCE: John Chalmers, MD, PhD, George Institute, Australia; Stephen MacMahon, DSc, PhD, George Institute, Australia; Mark Woodward, PhD, George Institute, Australia; Aichi: Hiroshi Yatsuya, MD, PhD, Nagoya University, Japan; Kentaro Yamashita, MD, Nagoya University, Japan; Hideaki Toyoshima, MD, PhD, Nagoya University, Japan; Koji Tamakoshi, MD, PhD, Nagoya University, Japan; ARIC: Josef Coresh, MD, PhD, Johns Hopkins University, United States; Brad C. Astor, PhD, MPH, University of Wisconsin, United States; Kunihiro Matsushita, MD, PhD, Johns Hopkins University, United States; Yingying Sang, MS, Johns Hopkins University, United States; AusDiab: Robert C. Atkins, FRACP, DSc, Monash University, Australia; Kevan R. Polkinghorne, FRACP, MClinEpi, PhD, Monash University, Australia; Steven Chadban, FRACP, PhD, University of Sydney, Australia; Beaver Dam CKD: Anoop Shankar, MD, PhD, West Virginia University, United States; Ronald Klein, MD, MPH,University of Wisconsin, United States; Barbara E.K. Klein, MD, MPH,University of Wisconsin, United States; Kristine E. Lee, MS, University of Wisconsin, United States; Beijing Cohort: Haiyan Wang, MD, Peking University First Hospital, China; Fang Wang, MD, Peking University First Hospital, China; Luxia Zhang, MD, MPH, Peking University First Hospital, China; Li Zuo, MD, Peking University First Hospital, China; British Columbia CKD: Adeera Levin, MD, FRCPC, BC Provincial Renal Agency and University of British Columbia, Canada; Ognjenka Djurdjev, MSc, BC Provincial Renal Agency and Provincial Health Services Authority, Canada; CARE: Marcello Tonelli, MD, SM, University of Alberta, Canada; Frank M. Sacks, MD,Harvard School of Public Health, United States; Gary C. Curhan, MD, ScD, Harvard School of Medicine, United States; CHS: Michael Shlipak, MD, MPH, University of California and San Francisco VA Medical Center, United States; Carmen Peralta, MD, MAS, University of California and San Francisco VA Medical Center, United States; Ronit Katz, DPhil, University of Washington, United States; Linda F. Fried, MD, MPH, VA Pittsburgh Healthcare System, United States; CIRCS: Hiroyasu Iso, MD,PhD, MPH, Osaka University, Japan;Akihiko Kitamura, MD, PhD, Osaka Medical Center, Japan; Tetsuya Ohira, MD, PhD, Osaka University, Japan; KazumasaYamagishi, MD, PhD, University of Tsukuba, Japan; COBRA: Tazeen H. Jafar, MD, MPH, Aga Khan University, Pakistan; Muhammad Islam, MSc, Aga Khan University, Pakistan; Juanita Hatcher, PhD, Aga Khan University, Pakistan; Neil Poulter, MSc, FRCP, Imperial College London, United Kingdom; Nish Chaturvedi, MD, MRCP, Imperial College London, United Kingdom; CRIB: Martin J. Landray, PhD, FRCP, University of Oxford, United Kingdom; Jonathan Emberson, PhD, University of Oxford, United Kingdom; John N. Townend, MD, FRCP, Queen Elizabeth Hospital Birmingham, United Kingdom; David C. Wheeler, MD, FRCP, University College London, United Kingdom; ESTHER: Dietrich Rothenbacher, MD, MPH, German Cancer Research Center and University of Ulm, Germany; Hermann Brenner, MD, MPH, German Cancer Research Center, Germany; Heiko Müller, PhD, German Cancer Research Center, Germany; Ben Schöttker, PhD, German Cancer Research Center, Germany; Framingham: Caroline S. Fox, MD, MPH, National Heart, Lung, and Blood Institute, United States; Shih-Jen Hwang, PhD, National Heart, Lung, and Blood Institute, United States; James B. Meigs, MD, MPH, Massachusetts General Hospital, United States; Geisinger: Robert M. Perkins, MD, Geisinger Medical Center, United States; 
GLOMMS-1 Study:Nick Fluck, BSc, MBBC, DPhil, FRCP, University of Aberdeen, United Kingdom;Laura E. Clark, MBChB, MRCP, MD, University of Aberdeen, United Kingdom;Gordon Prescott, BSc MSc PhD CStat, University of Aberdeen, United Kingdom; Angharad Marks, MBBCh MRCP MSc, University of Aberdeen, United Kingdom; Corri Black, MBChB, MRCP, MSc, MFPH, FFPH, University of Aberdeen, United Kingdom; Gubbio: Massimo Cirillo, MD, University of Salerno, Italy; HUNT: Stein Hallan, MD, $\mathrm{PhD}$, Norwegian University of Science and Technology and St Olav University, Norway; Knut Aasarød, MD, PhD, NorwegianUniversity of Science and Technology and St Olav University Hopstial, Norway; Cecilia M. Øien, MD, PhD, Norwegian University of Science and Technology, Norway; Maria Radtke, MD, PhD, Norwegian University of Science and Technology and St Olavs University Hospital, Norway; IPHS: Fujiko Irie, MD, PhD, Ibaraki Prefectural Office, Japan; Hiroyasu Iso, MD, PhD, MPH, Osaka University, Japan; Toshimi Sairenchi, PhD, Dokkyo Medical University School of Medicine, Japan; Kazumasa Yamagishi, MD, PhD, University of Tsukuba, Japan; Kaiser Permanente NW: David H. Smith, RPh, PhD, Kaiser Permanente Northwest, United States; Jessica W. Weiss, MD, Oregon Health and Science University, United States; Eric S. Johnson, PhD, Kaiser Permanente Northwest, United States; Micah L. Thorp, DO, MPH, Kaiser Permanente Northwest, United States; KEEP: Allan J. Collins, MD, Minneapolis Medical Research Foundation, Unites States; Joseph A. Vassalotti, MD, U.S. National Kidney Foundation, United States; Suying Li, PhD, Minneapolis Medical Research Foundation, Unites States; Shu-Cheng Chen, MS, Minneapolis Medical Research Foundation, Unites States; KP Hawaii: Brian J. Lee, MD, Kaiser PermanenteHawaii Region, United States; MASTERPLAN: Jack F. Wetzels, MD, Radboud University Nijmegen Medical Centre, The Netherlands;Peter J. Blankestijn, MD, PhD, University Medical Center Utrecht, The Netherlands; Arjan D. van Zuilen, MD, University Medical Center Utrecht, The Netherlands; MDRD: Mark Sarnak, MD, MS, Tufts Medical Center, United States; Andrew S. Levey, MD, Tufts Medical Center, United States; Vandana Menon, MD, PhD, Tufts Medical Center, United States; MESA: Michael Shlipak, MD, MPH, University of California and San Francisco VA Medical Center, United States; Mark Sarnak, MD, MS, Tufts Medical Center, United States;Carmen Peralta, MD, MAS, University of California and San Francisco VA Medical Center, United States; Ronit Katz, DPhil, University of Washington, United States; Holly J. Kramer, MD, MPH, Loyola University Medical Center, United States; Ian H. de Boer, MD, MS, University of Washington, United States; MMKD: Florian Kronenberg, MD, Innsbruck Medical University, Austria; Barbara Kollerits, PhD, MPH, Innsbruck Medical University, Austria; Eberhard Ritz, MD, Heidelberg Nierenzentrum, Germany; MRC Older People: Paul Roderick, MD, University of Southampton, United Kingdom; Dorothea Nitsch, MD, MSc, London School of Hygiene \& Tropical Medicine, United Kingdom;Astrid Fletcher, PhD, London School of Hygiene \& Tropical Medicine, United Kingdom; Christopher Bulpitt, MD, Imperial College Hammersmith Campus, United Kingdom; MRFIT: Areef Ishani, MD, MS, Minneapolis VA Health Care System, United States; James D. Neaton, PhD, University of Minnesota, United States; NephroTest: Marc Froissart, MD, PhD, Paris Descartes University, France; Benedicte Stengel, MD, PhD, Centre for Research in Epidemiology and Population Health and University of Paris Sud-11, France; Marie Metzger, PhD, Centre for Research in Epidemiology and Population Health and University of Paris Sud-11, France; Jean-Philippe Haymann, MD, PhD, Assistance Publique-Hôpitaux de Paris, France; Pascal Houillier, MD, $\mathrm{PhD}$, Assistance Publique-Hôpitaux de Paris, Paris Descartes University, France; Martin Flamant, MD, PhD, Assistance Publique-Hôpitaux de Paris, France; NHANES III: Brad C. Astor, PhD, MPH, University of Wisconsin, United States; Josef Coresh, MD, PhD, Johns Hopkins University, United States; Kunihiro Matsushita, MD, PhD, Johns Hopkins University, United States; Ohasama: Takayoshi Ohkubo, MD, PhD, Shiga University of Medical Science, Japan; Hirohito Metoki, PhD, MD, Tohoku University, Japan; Masaaki 
Nakayama, MD, PhD, Fukushima Medical University, Japan; Masahiro Kikuya, MD, PhD, Tohoku University, Japan; Yutaka Imai, MD, PhD, Tohoku University, Japan; Okinawa 83/93:Kunitoshi Iseki, MD, University Hospital of the Ryukyus, Japan; Pima Indian: Robert G. Nelson, MD, PhD, National Institute of Diabetes and Digestive and Kidney Diseases, United States; William C. Knowler MD, DrPh, National Institute of Diabetes and Digestive and Kidney Diseases, United States; PREVEND: Ron T. Gansevoort, MD, PhD, University Medical Center Groningen, The Netherlands; Paul E. de Jong, MD, PhD, University Medical Center Groningen, The Netherlands; Bakhtawar K. Mahmoodi, MD, PhD, University Medical Center Groningen, The Netherlands; Stephan J.L. Bakker, MD, $\mathrm{PhD}$, University Medical Center Groningen, The Netherlands; Rancho Bernardo: Simerjot Kaur Jassal, MD, University of California San Diego and VA San Diego Healthcare, United States; Elizabeth Barrett-Connor, MD, University of California San Diego, United States; Jaclyn Bergstrom, MS, University of California San Diego, United States; RENAAL: Hiddo J. Lambers Heerspink, PharmD, PhD, University Medical Center Groningen, The Netherlands; Barry E. Brenner, MD, PhD, Brigham and Women's Hospital and Harvard School of Medicine, United States; Dick de Zeeuw, MD, PhD, University Medical Center Groningen, The Netherlands; Renal REGARDS: David G. Warnock, MD, University of Alabama at Birmingham, United States; Paul Muntner, PhD, University of Alabama at Birmingham, United States; Suzanne Judd, PhD, University of Alabama at Birmingham, United States; William McClellan, MD, MPH, Emory University, United States; Severance: Sun Ha Jee, PhD, Yonsei University, Republic of Korea; Heejin Kimm, MD, PhD, Yonsei University, Republic of Korea; Jaeseong Jo, BS, Yonsei University, Republic of Korea;Yejin Mok, Yonsei University, Republic of Korea; Eunmi Choi, Yonsei University, Republic of Korea; STENO: Peter Rossing, MD, DMSC, Steno Diabetes Center, Denmark; Hans-HenrikParving, MD, DMSC, University Hospital of Copenhagen, Denmark;

Sunnybrook: NavdeepTangri, MD, $\mathrm{PhD}(\mathrm{C})$, FRCPC, University of Manitoba, Canada; David Naimark, FRCPC, University of Toronto, Canada; Taiwan GP: Chi-Pang Wen, MD, DrPH, China Medical University Hospital, Taiwan; Sung-Feng Wen, MD, University of Wisconsin, United States; Chwen-Keng Tsao, BS, MJ Health Management Institution, Taiwan; Min-Kuang Tsai, MS, National Health Research Institutes, Taiwan; ULSAM: Johan Ärnlöv, MD, PhD, Uppsala University, Sweden; Lars Lannfelt, MD, PhD, Uppsala University Hospital, Sweden; Anders Larsson, MD, PhD, Uppsala University, Sweden; ZODIAC: Henk J. Bilo, MD, PhD, Isala Clinics, The Netherlands; Hanneke Joosten, MD, University Medical Center Groningen, The Netherlands; Nanno Kleefstra, MD, PhD, Isala Clinics, The Netherlands; Klaas H. Groenier, PhD, Isala Clinics, The Netherlands; Iefke Drion, MD, Isala Clinics, The Netherlands;

\section{CKD-PC Steering Committee}

Brad C. Astor, PhD, MPH, University of Wisconsin, United States; Josef Coresh (Chair), MD, PhD, Johns Hopkins University, United States; Ron T. Gansevoort, MD, PhD, University Medical Center Groningen, The Netherlands; Brenda R. Hemmelgarn, MD, PhD, University of Calgary, Canada; Paul E. de Jong, MD, PhD, University Medical Center Groningen, The Netherlands; Andrew S. Levey, MD, Tufts Medical Center, United States; Adeera Levin, MD, FRCPC, BC Provincial Renal Agency and University of British Columbia, Canada; Kunihiro Matsushita, MD, PhD, Johns Hopkins University, United States; Chi-Pang Wen, MD, DrPH, China Medical University Hospital, Taiwan; Mark Woodward, PhD, George Institute, Australia;

\section{CKD-PC Data Coordinating Center}

Shoshana H. Ballew (Coordinator), PhD, Johns Hopkins University, United States; Josef Coresh (Principal investigator), MD, PhD, Johns Hopkins University, United States; Morgan 
Grams, MD, MHS, Johns Hopkins University, United States; Bakhtawar K. Mahmoodi, MD, PhD, Johns Hopkins University, United States; Kunihiro Matsushita (Director), MD, PhD, Johns Hopkins University, United States; Yingying Sang (Lead programmer), MS, Johns Hopkins University, United States; Mark Woodward (Senior statistician), PhD, George Institute, Australia; administrative support: Laura Camarata, BA, Johns Hopkins University, United States; Xuan Hui, BMed, Johns Hopkins University, United States; Jennifer Seltzer, BS, Johns Hopkins University, United States; Heather Winegrad, Johns Hopkins University, United States;

\section{Role of the Sponsor}

The sponsors had no role in the design and conduct of the study; in the collection, analysis, and interpretation of the data; or in the preparation, review, or approval of the manuscript.

\section{References}

1. National Kidney Foundation. K/DOQI clinical practice guidelines for chronic kidney disease: evaluation, classification, and stratification. Am J Kidney Dis. 2002; 39(2 Suppl 1):S1-266. [PubMed: 11904577]

2. Crowe E, Halpin D, Stevens P, on behalf of the Guideline Development G. Early identification and management of chronic kidney disease: summary of NICE guidance. BMJ. 2008; 337(sep29_1):a1530. [PubMed: 18824486]

3. Matsushita K, van der Velde M, Astor BC, et al. Association of estimated glomerular filtration rate and albuminuria with all-cause and cardiovascular mortality in general population cohorts: a collaborative meta-analysis. Lancet. 2010; 375(9731):2073-2081. [PubMed: 20483451]

4. van der Velde M, Matsushita K, Coresh J, et al. Lower estimated glomerular filtration rate and higher albuminuria are associated with all-cause and cardiovascular mortality. A collaborative metaanalysis of high-risk population cohorts. Kidney Int. 2011; 79(12):1341-1352. [PubMed: 21307840]

5. Gansevoort RT, Matsushita K, van der Velde M, et al. Lower estimated GFR and higher albuminuria are associated with adverse kidney outcomes. A collaborative meta-analysis of general and high-risk population cohorts. Kidney Int. 2011; 80(1):93-104. [PubMed: 21289597]

6. Astor BC, Matsushita K, Gansevoort RT, et al. Lower estimated glomerular filtration rate and higher albuminuria are associated with mortality and end-stage renal disease. A collaborative meta-analysis of kidney disease population cohorts. Kidney Int. 2011; 79(12):1331-1340. [PubMed: 21289598]

7. The College of American Pathologists. [Accessed March, 6, 2012] Current Status Of Reporting Estimated Glomerular Filtration Rate (eGFR) for Adults. http://www.cap.org/apps/docs/committees/ chemistry/current_status_of_reporting_eGF R_2011.pdf

8. Miller WG. Estimating glomerular filtration rate. Clin Chem Lab Med. 2009; 47(9):1017-1019. [PubMed: 19728841]

9. Levey AS, Coresh J, Greene T, et al. Using standardized serum creatinine values in the modification of diet in renal disease study equation for estimating glomerular filtration rate. Ann Intern Med. 2006; 145(4):247-254. [PubMed: 16908915]

10. Levey AS, Stevens LA, Schmid CH, et al. A new equation to estimate glomerular filtration rate. Ann Intern Med. 2009; 150(9):604-612. [PubMed: 19414839]

11. Tent H, Rook M, Stevens LA, et al. Renal function equations before and after living kidney donation: a within-individual comparison of performance at different levels of renal function. Clinical Journal of the American Society of Nephrology. 2010; 5(11):1960-1968. [PubMed: 20616162]

12. Jones GR. Use of the CKD-EPI equation for estimation of GFR in an Australian cohort. Pathology. 2010; 42(5):487-488. [PubMed: 20632832]

13. White CA, Akbari A, Doucette S, Fergusson D, Knoll GA. Estimating glomerular filtration rate in kidney transplantation: is the new chronic kidney disease epidemiology collaboration equation any better? Clin Chem. 2010; 56(3):474-477. [PubMed: 19959620] 
14. Cirillo M, Lombardi C, Luciano MG, Bilancio G, Anastasio P, De Santo NG. Estimation of GFR: a comparison of new and established equations. Am J Kidney Dis. 2010; 56(4):802-804. [PubMed: 20801570]

15. Eriksen BO, Mathisen UD, Melsom T, et al. Cystatin C is not a better estimator of GFR than plasma creatinine in the general population. Kidney Int. 2010; 78(12):1305-1311. [PubMed: 20844470]

16. Lane BR, Demirjian S, Weight CJ, Larson BT, Poggio ED, Campbell SC. Performance of the chronic kidney disease-epidemiology study equations for estimating glomerular filtration rate before and after nephrectomy. J Urol. 2010; 183(3):896-901. [PubMed: 20083272]

17. Michels WM, Grootendorst DC, Verduijn M, Elliott EG, Dekker FW, Krediet RT. Performance of the Cockcroft-Gault, MDRD, and new CKD-EPI formulas in relation to GFR, age, and body size. Clin J Am Soc Nephrol. 2010; 5(6):1003-1009. [PubMed: 20299365]

18. Murata K, Baumann NA, Saenger AK, Larson TS, Rule AD, Lieske JC. Relative Performance of the MDRD and CKD-EPI Equations for Estimating Glomerular Filtration Rate among Patients with Varied Clinical Presentations. Clin J Am Soc Nephrol. 2011; 6(8):1963-1972. [PubMed: 21737852]

19. Kukla A, El-Shahawi Y, Leister E, et al. GFR-estimating models in kidney transplant recipients on a steroid-free regimen. Nephrology Dialysis Transplantation. 2010; 25(5):1653-1661.

20. Rognant N, Lemoine S, Laville M, Hadj-Aissa A, Dubourg L. Performance of the Chronic Kidney Disease Epidemiology Collaboration Equation to Estimate Glomerular Filtration Rate in Diabetic Patients. Diabetes Care. 2011; 34(6):1320-1322. [PubMed: 21540431]

21. Matsushita K, Selvin E, Bash LD, Astor BC, Coresh J. Risk implications of the new CKD-EPI equation as compared to the MDRD Study equation for estimated glomerular filtration rate: the Atherosclerosis Risk in Communities (ARIC) Study. Am J Kidney Dis. 2010; 55(4):648-659. [PubMed: 20189275]

22. Stevens LA, Li S, Kurella Tamura M, et al. Comparison of the CKD Epidemiology Collaboration (CKD-EPI) and Modification of Diet in Renal Disease (MDRD) study equations: risk factors for and complications of CKD and mortality in the Kidney Early Evaluation Program (KEEP). Am J Kidney Dis. 2011; 57(3 Suppl 2):S9-16. [PubMed: 21338849]

23. Skali H, Uno H, Levey AS, Inker LA, Pfeffer MA, Solomon SD. Prognostic assessment of estimated glomerular filtration rate by the new Chronic Kidney Disease Epidemiology Collaboration equation in comparison with the Modification of Diet in Renal Disease Study equation. American Heart Journal. 2011; 162(3):548-554. [PubMed: 21884875]

24. White SL, Polkinghorne KR, Atkins RC, Chadban SJ. Comparison of the Prevalence and Mortality Risk of CKD in Australia Using the CKD Epidemiology Collaboration (CKD-EPI) and Modification of Diet in Renal Disease (MDRD) Study GFR Estimating Equations: The AusDiab (Australian Diabetes, Obesity and Lifestyle) Study. Am J Kidney Dis. 2010; 55(4):660-670. [PubMed: 20138414]

25. Carter JL, Stevens PE, Irving JE, Lamb EJ. Estimating glomerular filtration rate: comparison of the CKD-EPI and MDRD equations in a large UK cohort with particular emphasis on the effect of age. QJM. 2011; 104(10):839-847. [PubMed: 21652537]

26. van den Brand JAJG, van Boekel GAJ, Willems HL, Kiemeney LALM, den Heijer M, Wetzels JFM. Introduction of the CKD-EPI equation to estimate glomerular filtration rate in a Caucasian population. Nephrology Dialysis Transplantation. 2011; 26(10):3176-3181.

27. Mitsuhashi H, Yatsuya H, Matsushita K, et al. Uric acid and left ventricular hypertrophy in Japanese men. Circ J. 2009; 73(4):667-672. [PubMed: 19225200]

28. Shankar A, Klein R, Klein BE. The association among smoking, heavy drinking, and chronic kidney disease. Am J Epidemiol. 2006; 164(3):263-271. [PubMed: 16775042]

29. Zhang L, Zuo L, Xu G, et al. Community-based screening for chronic kidney disease among populations older than 40 years in Beijing. Nephrol. Dial. Transplant. 2007; 22(4):1093-1099. [PubMed: 17210584]

30. Shlipak MG, Katz R, Kestenbaum B, et al. Rate of kidney function decline in older adults: a comparison using creatinine and cystatin C. Am J Nephrol. 2009; 30(3):171-178. [PubMed: 19349699] 
31. Shimizu Y, Maeda K, Imano H, et al. Chronic kidney disease and drinking status in relation to risks of stroke and its subtypes: the Circulatory Risk in Communities Study (CIRCS). Stroke. 2011; 42(9):2531-2537. [PubMed: 21852604]

32. Jafar TH, Qadri Z, Hashmi S. Prevalence of microalbuminuria and associated electrocardiographic abnormalities in an Indo-Asian population. Nephrol. Dial. Transplant. 2009; 24(7):2111-2116. [PubMed: 19225011]

33. Zhang QL, Koenig W, Raum E, Stegmaier C, Brenner H, Rothenbacher D. Epidemiology of chronic kidney disease: results from a population of older adults in Germany. Prev Med. 2009; 48(2):122-127. [PubMed: 19041887]

34. Parikh NI, Hwang S-J, Larson MG, Levy D, Fox CS. Chronic Kidney Disease as a Predictor of Cardiovascular Disease (from the Framingham Heart Study). The American Journal of Cardiology. 2008; 102(1):47-53. [PubMed: 18572034]

35. Cirillo M, Lanti MP, Menotti A, et al. Definition of kidney dysfunction as a cardiovascular risk factor: use of urinary albumin excretion and estimated glomerular filtration rate. Arch Intern Med. 2008; 168(6):617-624. [PubMed: 18362254]

36. Hallan SI, Coresh J, Astor BC, et al. International comparison of the relationship of chronic kidney disease prevalence and ESRD risk. J Am Soc Nephrol. 2006; 17(8):2275-2284. [PubMed: 16790511]

37. Noda H, Iso H, Irie F, et al. Low-density lipoprotein cholesterol concentrations and death due to intraparenchymal hemorrhage: the Ibaraki Prefectural Health Study. Circulation. 2009; 119(16): 2136-2145. [PubMed: 19364982]

38. Bui AL, Katz R, Kestenbaum B, et al. Cystatin C and carotid intima-media thickness in asymptomatic adults: the Multi-Ethnic Study of Atherosclerosis (MESA). Am J Kidney Dis. 2009; 53(3):389-398. [PubMed: 18823684]

39. Roderick PJ, Atkins RJ, Smeeth L, et al. CKD and mortality risk in older people: a communitybased population study in the United Kingdom. Am J Kidney Dis. 2009; 53(6):950-960. [PubMed: 19394727]

40. Astor BC, Hallan SI, Miller ER 3rd, Yeung E, Coresh J. Glomerular filtration rate, albuminuria, and risk of cardiovascular and all-cause mortality in the US population. Am J Epidemiol. 2008; 167(10):1226-1234. [PubMed: 18385206]

41. Nakayama M, Metoki H, Terawaki H, et al. Kidney dysfunction as a risk factor for first symptomatic stroke events in a general Japanese population--the Ohasama study. Nephrol Dial Transplant. 2007; 22(7):1910-1915. [PubMed: 17395659]

42. Iseki K, Ikemiya Y, Iseki C, Takishita S. Proteinuria and the risk of developing end-stage renal disease. Kidney Int. 2003; 63(4):1468-1474. [PubMed: 12631363]

43. Iseki K, Kohagura K, Sakima A, et al. Changes in the demographics and prevalence of chronic kidney disease in Okinawa, Japan (1993 to 2003). Hypertens Res. 2007; 30(1):55-62. [PubMed: 17460372]

44. Hillege HL, Fidler V, Diercks GF, et al. Urinary albumin excretion predicts cardiovascular and noncardiovascular mortality in general population. Circulation. 2002; 106(14):1777-1782. [PubMed: 12356629]

45. Jassal SK, Kritz-Silverstein D, Barrett-Connor E. A Prospective Study of Albuminuria and Cognitive Function in Older Adults: The Rancho Bernardo Study. Am. J. Epidemiol. 2010; 171(3):277-286. [PubMed: 20061364]

46. Howard VJ, Cushman M, Pulley L, et al. The reasons for geographic and racial differences in stroke study: objectives and design. Neuroepidemiology. 2005; 25(3):135-143. [PubMed: 15990444]

47. Kimm H, Yun JE, Jo J, Jee SH. Low Serum Bilirubin Level as an Independent Predictor of Stroke Incidence: A Prospective Study in Korean Men and Women. Stroke. 2009; 40(11):3422-3427. [PubMed: 19713538]

48. Wen CP, Cheng TY, Tsai MK, et al. All-cause mortality attributable to chronic kidney disease: a prospective cohort study based on 462293 adults in Taiwan. Lancet. 2008; 371(9631):2173-2182. [PubMed: 18586172] 
49. Ingelsson E, Sundstrom J, Lind L, et al. Low-grade albuminuria and the incidence of heart failure in a community-based cohort of elderly men. Eur Heart J. 2007; 28(14):1739-1745. [PubMed: 17495987]

50. Patel A, MacMahon S, Chalmers J, et al. Effects of a fixed combination of perindopril and indapamide on macrovascular and microvascular outcomes in patients with type 2 diabetes mellitus (the ADVANCE trial): a randomised controlled trial. Lancet. 2007; 370(9590):829-840. [PubMed: 17765963]

51. Tonelli M, Jose P, Curhan G, Sacks F, Braunwald E, Pfeffer M. Proteinuria, impaired kidney function, and adverse outcomes in people with coronary disease: analysis of a previously conducted randomised trial. BMJ. 2006; 332(7555):1426. [PubMed: 16714328]

52. Jurkovitz CT, Qiu Y, Wang C, Gilbertson DT, Brown WW. The Kidney Early Evaluation Program (KEEP): program design and demographic characteristics of the population. Am J Kidney Dis. 2008; 51(4 Suppl 2):S3-12. [PubMed: 18359405]

53. Lee BJ, Forbes K. The role of specialists in managing the health of populations with chronic illness: the example of chronic kidney disease. BMJ. 2009; 339:b2395. [PubMed: 19586983]

54. Ishani A, Grandits GA, Grimm RH, et al. Association of single measurements of dipstick proteinuria, estimated glomerular filtration rate, and hematocrit with 25-year incidence of endstage renal disease in the multiple risk factor intervention trial. J Am Soc Nephrol. 2006; 17(5): 1444-1452. [PubMed: 16611715]

55. Pavkov ME, Knowler WC, Hanson RL, Bennett PH, Nelson RG. Predictive power of sequential measures of albuminuria for progression to ESRD or death in Pima Indians with type 2 diabetes. Am J Kidney Dis. 2008; 51(5):759-766. [PubMed: 18436086]

56. Bilo HJ, Logtenberg SJ, Joosten H, Groenier KH, Ubink-Veltmaat LJ, Kleefstra N. Modification of diet in renal disease and Cockcroft-Gault formulas do not predict mortality (ZODIAC-6). Diabet Med. 2009; 26(5):478-482. [PubMed: 19646186]

57. Wright JT Jr. Bakris G, Greene T, et al. Effect of blood pressure lowering and antihypertensive drug class on progression of hypertensive kidney disease: results from the AASK trial. JAMA. 2002; 288(19):2421-2431. [PubMed: 12435255]

58. Levin A, Djurdjev O, Beaulieu M, Er L. Variability and risk factors for kidney disease progression and death following attainment of stage 4 CKD in a referred cohort. Am J Kidney Dis. 2008; 52(4):661-671. [PubMed: 18805347]

59. Landray MJ, Thambyrajah J, McGlynn FJ, et al. Epidemiological evaluation of known and suspected cardiovascular risk factors in chronic renal impairment. Am J Kidney Dis. 2001; 38(3): 537-546. [PubMed: 11532686]

60. Perkins RM, Bucaloiu ID, Kirchner HL, Ashouian N, Hartle JE, Yahya T. GFR decline and mortality risk among patients with chronic kidney disease. Clin J Am Soc Nephrol. 2011; 6(8): 1879-1886. [PubMed: 21685022]

61. Marks A, Black C, N F, et al. Translating chronic kidney disease epidemiology into patient care the individual/public health risk paradox. Nephrol Dial Transplant. In Press in CKD special edition.

62. Keith DS, Nichols GA, Gullion CM, Brown JB, Smith DH. Longitudinal follow-up and outcomes among a population with chronic kidney disease in a large managed care organization. Archives of internal medicine. 2004; 164(6):659-663. [PubMed: 15037495]

63. Van Zuilen AD, Wetzels JF, Bots ML, Van Blankestijn PJ. MASTERPLAN: study of the role of nurse practitioners in a multifactorial intervention to reduce cardiovascular risk in chronic kidney disease patients. J Nephrol. 2008; 21(3):261-267. [PubMed: 18587712]

64. Klahr S, Levey AS, Beck GJ, et al. The effects of dietary protein restriction and blood-pressure control on the progression of chronic renal disease. Modification of Diet in Renal Disease Study Group. N Engl J Med. 1994; 330(13):877-884. [PubMed: 8114857]

65. Kronenberg F, Kuen E, Ritz E, et al. Lipoprotein(a) serum concentrations and apolipoprotein(a) phenotypes in mild and moderate renal failure. J Am Soc Nephrol. 2000; 11(1):105-115. [PubMed: 10616846]

66. Moranne O, Froissart M, Rossert J, et al. Timing of onset of CKD-related metabolic complications. J Am Soc Nephrol. 2009; 20(1):164-171. [PubMed: 19005010] 
67. Brenner BM, Cooper ME, de Zeeuw D, et al. Effects of losartan on renal and cardiovascular outcomes in patients with type 2 diabetes and nephropathy. The New England journal of medicine. 2001; 345(12):861-869. [PubMed: 11565518]

68. Jorsal A, Tarnow L, Frystyk J, et al. Serum adiponectin predicts all-cause mortality and end stage renal disease in patients with type I diabetes and diabetic nephropathy. Kidney Int. 2008; 74(5): 649-654. [PubMed: 18496510]

69. Tangri N, Stevens LA, Griffith J, et al. A predictive model for progression of chronic kidney disease to kidney failure. JAMA. 2011; 305(15):1553-1559. [PubMed: 21482743]

70. Levey AS, Coresh J, Greene T, et al. Expressing the Modification of Diet in Renal Disease Study Equation for estimating glomerular filtration rate with standardized serum creatinine values. Clin Chem. 2007; 53(4):766-772. [PubMed: 17332152]

71. Pencina MJ, D'Agostino RB. Overall C as a measure of discrimination in survival analysis: model specific population value and confidence interval estimation. Stat Med. 2004; 23(13):2109-2123. [PubMed: 15211606]

72. Pencina MJ, D’Agostino RB Sr. D’Agostino RB Jr. Vasan RS. Evaluating the added predictive ability of a new marker: from area under the ROC curve to reclassification and beyond. Stat Med. 2008; 27(2):157-172. discussion 207-112. [PubMed: 17569110]

73. Cook NR. Use and misuse of the receiver operating characteristic curve in risk prediction. Circulation. 2007; 115(7):928-935. [PubMed: 17309939]

74. Stevens LA, Claybon MA, Schmid CH, et al. Evaluation of the Chronic Kidney Disease Epidemiology Collaboration equation for estimating the glomerular filtration rate in multiple ethnicities. Kidney International. 2010; 79(5):555-562. [PubMed: 21107446]

75. Teo BW, Xu H, Wang D, et al. GFR estimating equations in a multiethnic asian population. American Journal of Kidney Diseases. 2011; 58(1):56-63. [PubMed: 21601325]

76. Levey AS, de Jong PE, Coresh J, et al. The definition, classification, and prognosis of chronic kidney disease: a KDIGO Controversies Conference report. Kidney Int. 2011; 80(1):17-28. [PubMed: 21150873]

77. Tonelli M, Muntner P, Lloyd A, et al. Using proteinuria and estimated glomerular filtration rate to classify risk in patients with chronic kidney disease: a cohort study. Ann Intern Med. 2011; 154(1):12-21. [PubMed: 21200034]

78. Shlipak MG, Praught ML, Sarnak MJ. Update on cystatin C: new insights into the importance of mild kidney dysfunction. Curr Opin Nephrol Hypertens. 2006; 15(3):270-275. [PubMed: 16609294]

79. Astor BC, Levey AS, Stevens LA, Van Lente F, Selvin E, Coresh J. Method of glomerular giltration rate estimation affects prediction of mortality risk. J Am Soc Nephrol. 2009; 20(10): 2214-2222. [PubMed: 19762497] 

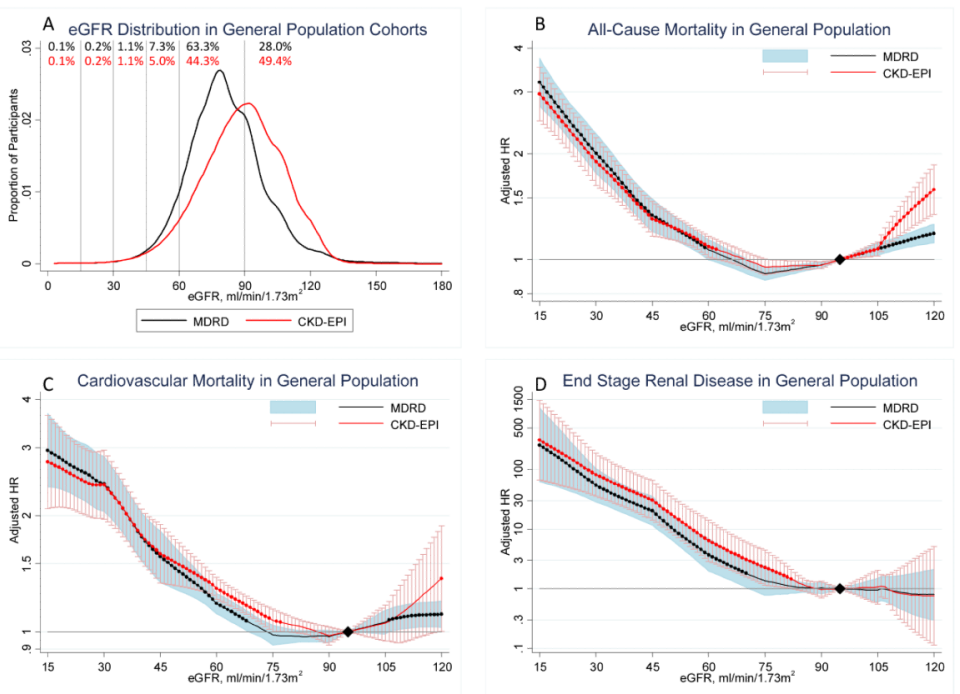

Figure 1.

Distribution based on kernel density estimation (proportion is for each integer eGFR) (A), and adjusted hazard ratios and 95\% CIs (shaded areas or whisker plots) of all-cause mortality (B), cardiovascular mortality (C), and ESRD (D) according to eGFR by the CKDEPI equation (red line) and the MDRD equation (black line) with eGFR $95 \mathrm{ml} / \mathrm{min} / 1.73 \mathrm{~m}^{2}$ as a reference (diamond). Vertical lines in panel A define GFR categories used for CKD staging. ${ }^{1,2}$ Dots in panels B-D represent statistical significance $(P<0.05)$. *Adjustments were for age, sex, race/ethnicity, smoking, history of CVD, systolic blood pressure, diabetes, serum total cholesterol concentration, body mass index, and albuminuria (log-ACR, $\log$ PCR or categorical dipstick proteinuria [negative, trace, $1+, 2+]$ ). 


\begin{tabular}{|c|c|c|c|c|c|c|}
\hline \multicolumn{7}{|c|}{ CKD-EPI øGFR } \\
\hline & 290 & 60 to 89 & 45 to 59 & 30 to 44 & 151029 & \\
\hline 290 & 259006 & $3239(1.2)$ & & & & 263145 \\
\hline 60 to 89 & 204187 (34.3) & 389845 & 964 (0.2) & & & 594996 \\
\hline 45 to 59 & & $23908(34.7)$ & 44161 & $804(1.2)$ & & 6873 \\
\hline 30 to 44 & & & \begin{tabular}{|l|}
1476 \\
{$[13.7$}
\end{tabular} & 9100 & $231(2.1)$ & 10807 \\
\hline 15 to 29 & & & & $89(4.8)$ & $177 / 2$ & 1861 \\
\hline & Up & ward/downwar & d reclassificatio & n (\%) & & \\
\hline & 464093 & 416992 & 46601 & 9993 & 2003 & \\
\hline
\end{tabular}

Figure 2.

Reclassification across eGFR categories by the CKD-EPI equation from eGFR categories based on the MDRD Study equation in the general population cohorts. The blue and red bars indicate upward reclassification to a higher eGFR category and downward reclassification to a lower eGFR category, respectively. Data are given as number (percentage) of participants who were reclassified. 


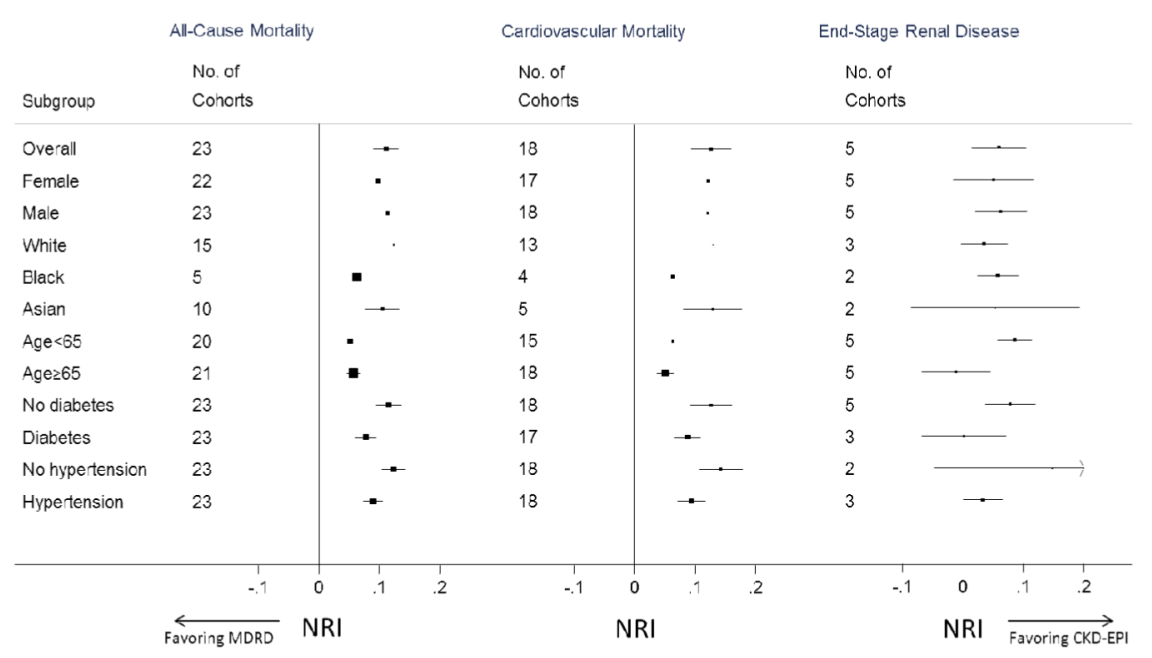

Figure 3.

Meta-analyzed NRI (middle of data marker) and 95\% CI (horizontal line) for the three outcomes based on eGFR categories overall and in subgroups according to demographic variables included in both equations and presence or absence of diabetes and hypertension (general population cohorts). The sizes of the data markers are proportional to the inverse of the variance of the NRIs. NRI was calculated as follows: NRI = Pr(down to lower eGFR category|events $)+\operatorname{Pr}$ (up to higher eGFR category|no events) $-\operatorname{Pr}$ (down to lower eGFR category|no events) - Pr(up to higher eGFR category|events). Positive NRI values favor the CKD-EPI equation. 


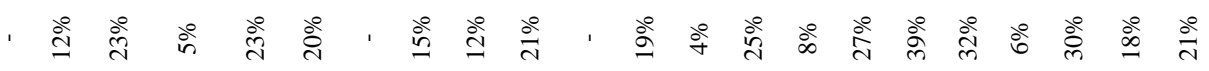

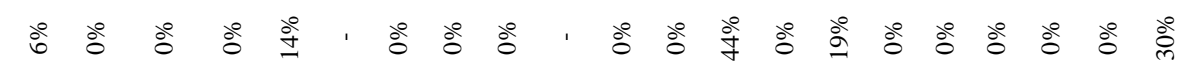

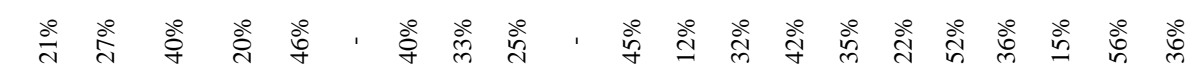

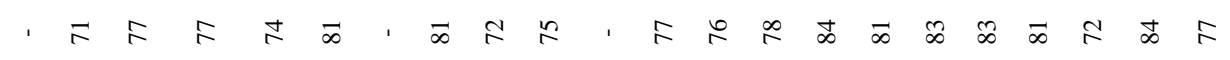

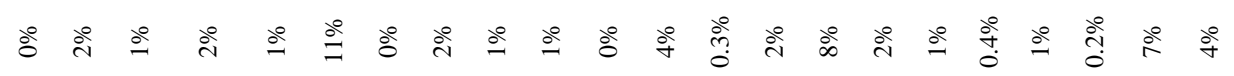

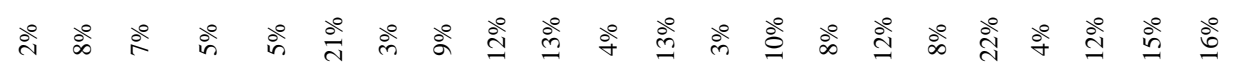

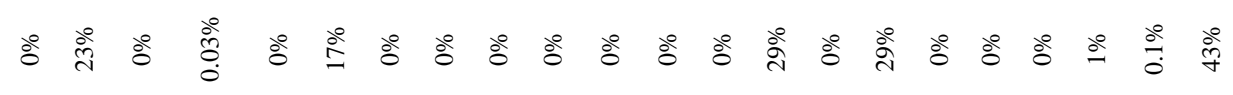

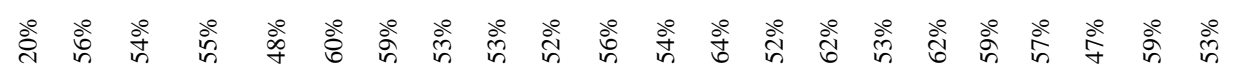

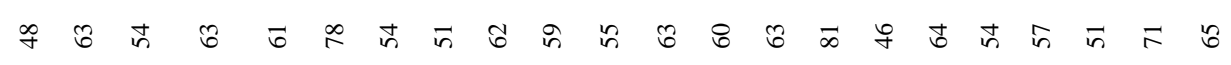

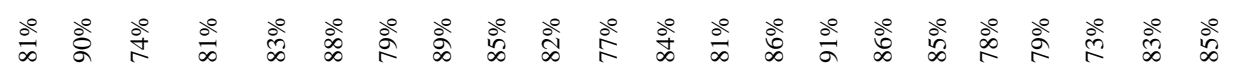

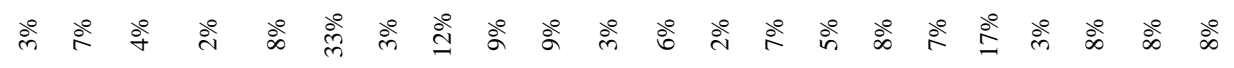

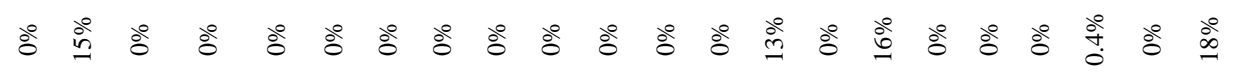

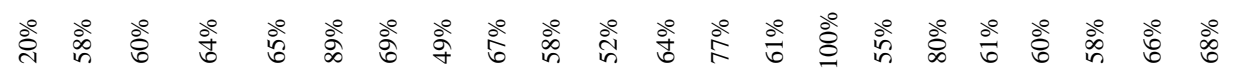

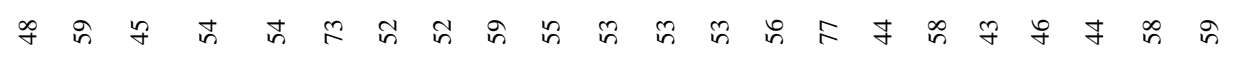

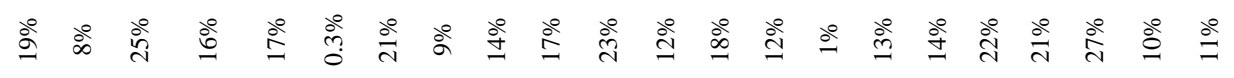

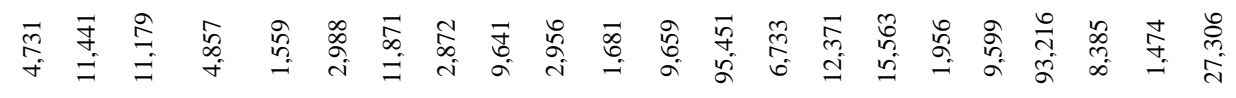




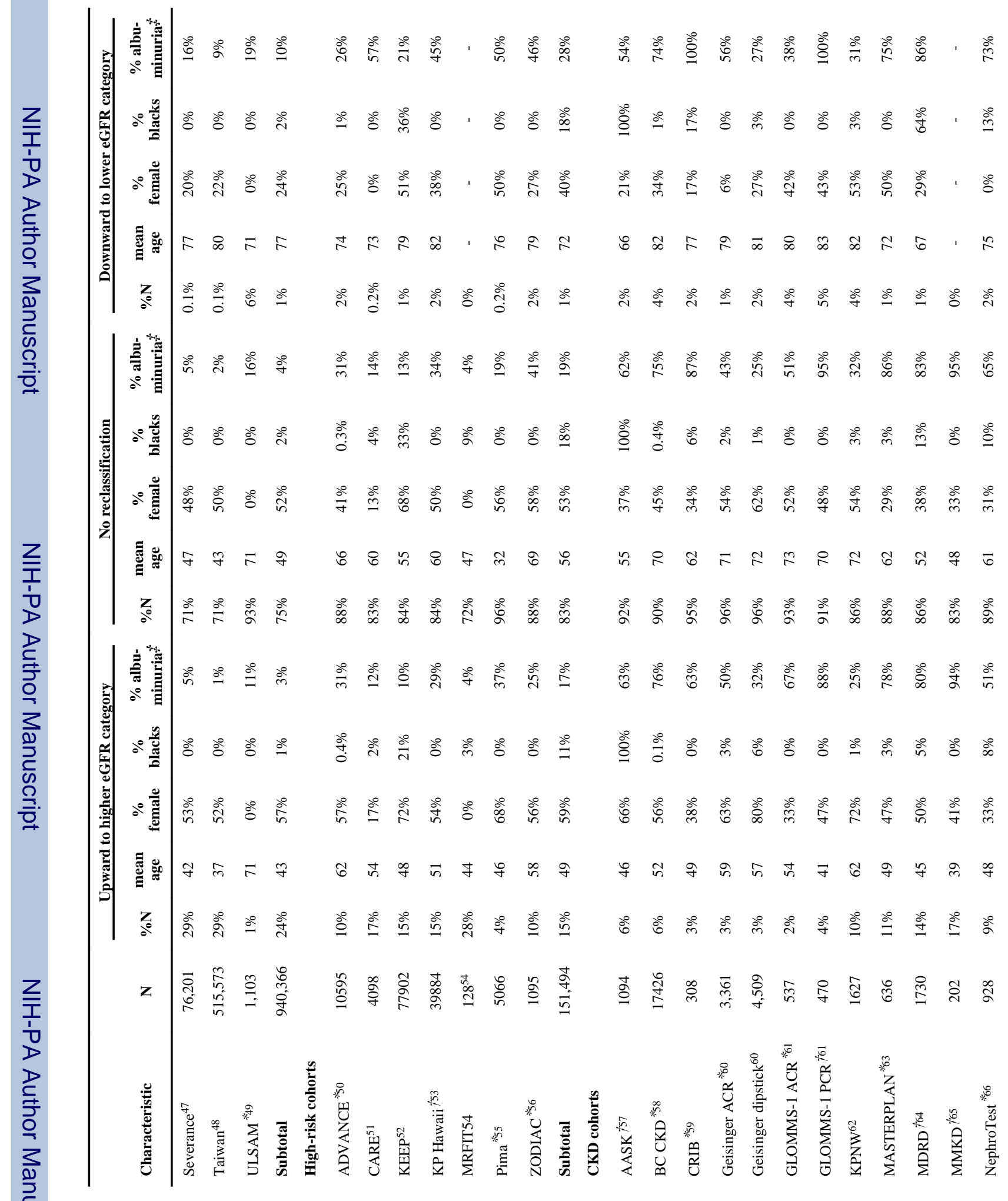




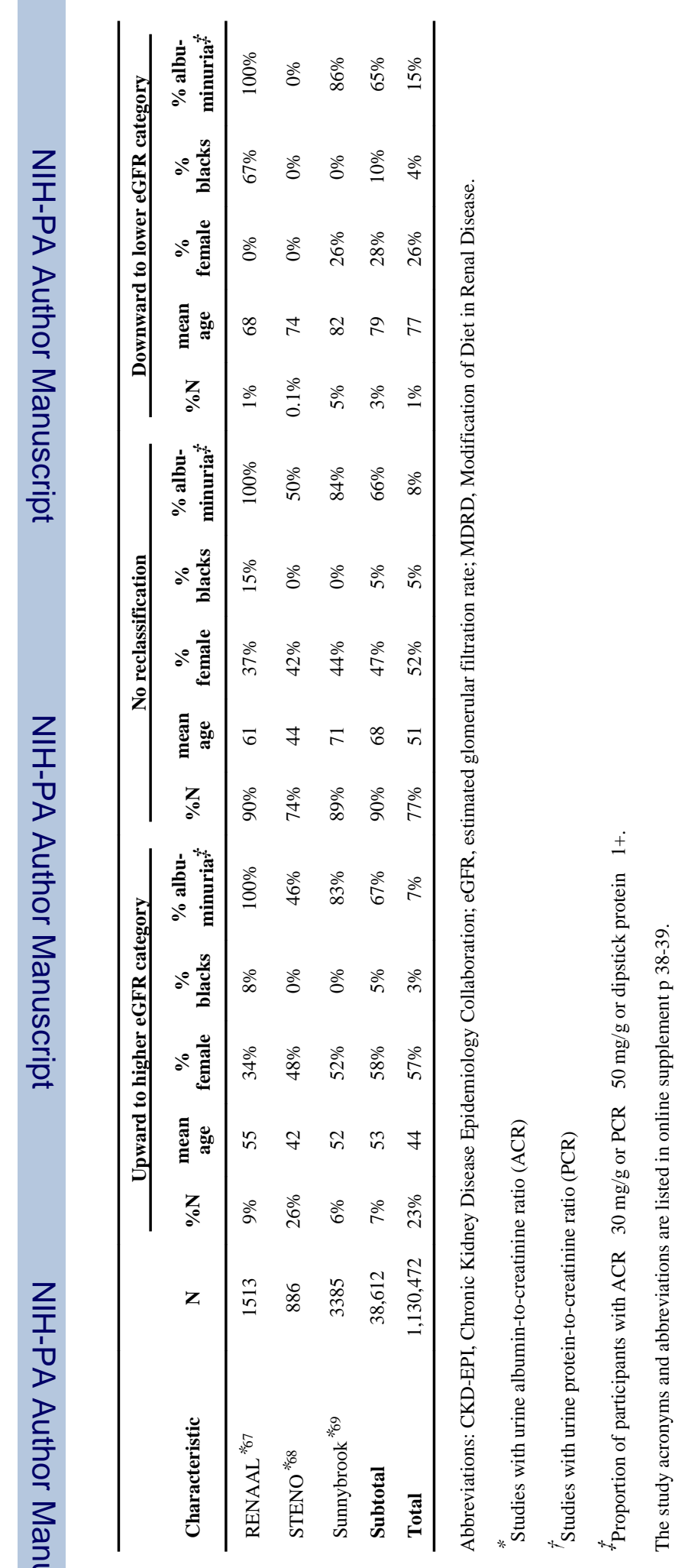




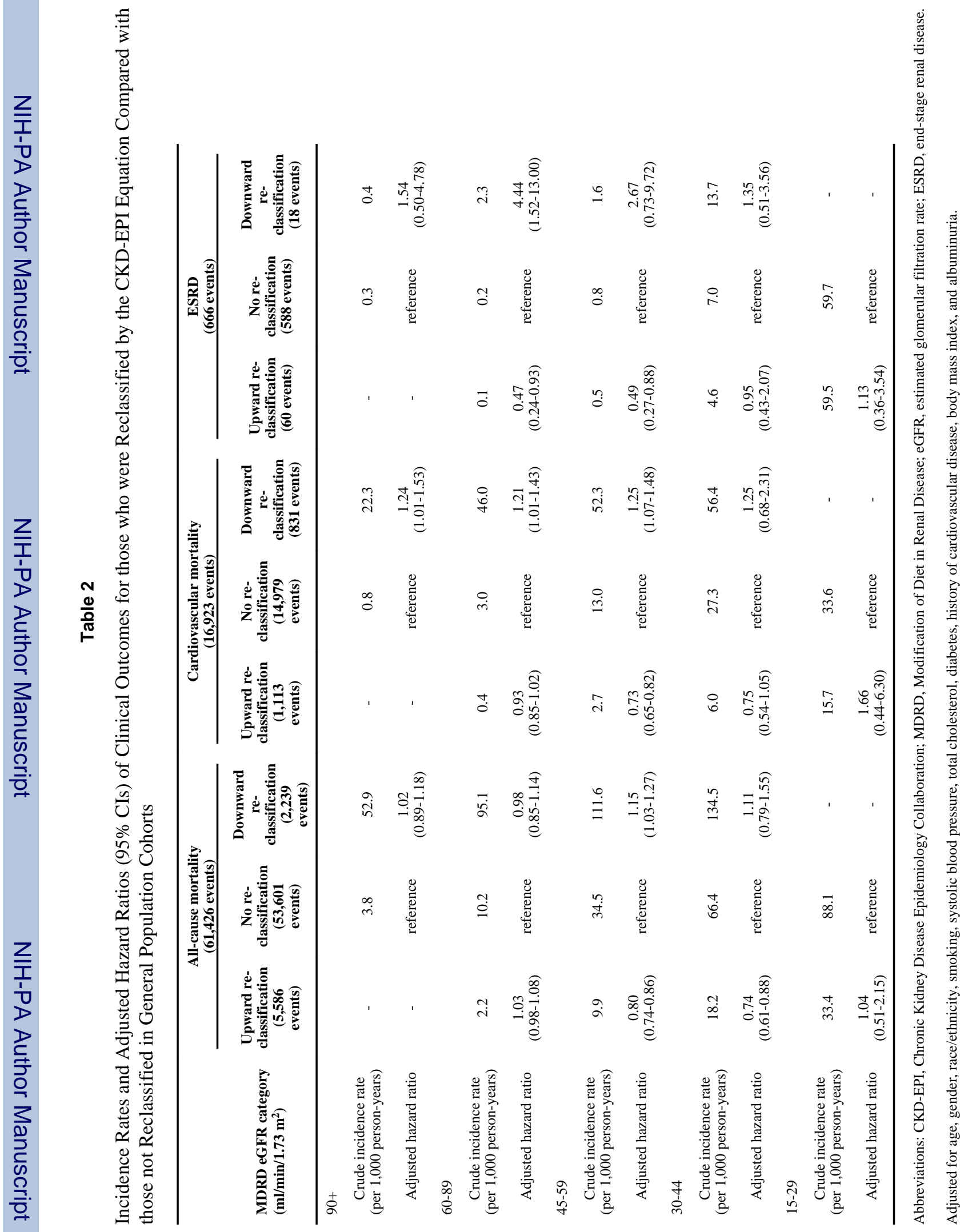

